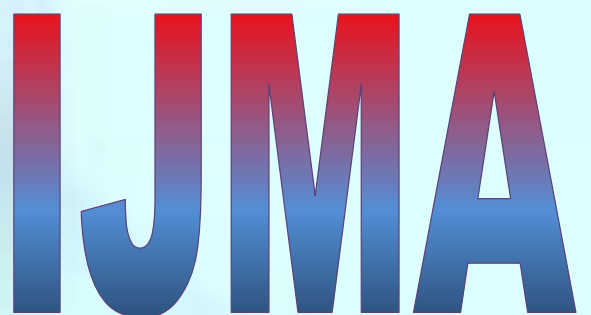

INTERNATIONAL

Journal of MEdical

\section{ARTS}

Volume 3, Issue 1 (Winter 2021)

http://ijma.journals.ekb.eg/

Print ISSN: 2636-4174

Online ISSN: 2682-3780

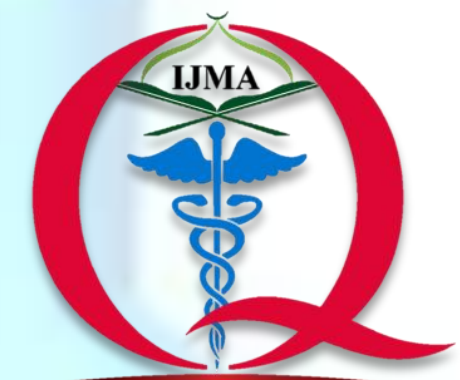

International Jounnal of Medical Arts

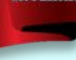




\section{About IJMA}

- International Journal of Medical Arts is the Official Journal of the Damietta Faculty of Medicine, Al-Azhar University, Egypt

- The First Issue was published in July 2019

- It is an International, Open Access, Double-blind, Peerreviewed Journal

- Published four times a year

- Published under the following license: Creative Commons Attribution-ShareAlike 4.0 International Public License (CC BY-SA 4.0). It had updated from the Creative Commons license [CC BY] in volume 2, Issue 4, October 2020

- The Egyptian Knowledge Bank hosts the web site of IJMA

- The Egyptian Knowledge Bank supports IJMA

- IJMA is indexed in the "Directory of Open Access Journals" Indexed on 15 January 2021.

- IJMA follows the regulations of the International Committee of Medical Journal Editors (list date 1/21/20)

- IJMA is a member of The International Society of Managing and Technical Editors

- IJMA is listed in Index Copernicus

- IJMA is listed in Publons, as EKB is an official partner with Clarivate Analytics
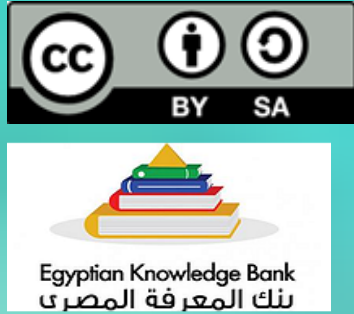

\section{DOAJ}

CMNE

ISMTE

INDEX COPERNICUS

publons 
International Journal of Medical Arts 2021; 3 [1]: 1119-1124.

Available online at Journal Website

Original article

\title{
The role of Trans-abdominal Ultrasound in Assessing Disease Activity and Severity in Ulcerative Colitis
}

\author{
Ragab Mahmoud E Ragab[1]; Mohamed Heiza[1]; Khaled Elmola[1]; Mostafa M Shaqueer[2]
}

Department of Hepatology, Gastroenterology and Infectious Diseases, Damietta Faculty of Medicine, Al-Azhar University, Egypt ${ }^{[1]}$

Department of Radiology, Damietta Faculty of Medicine, Al-Azhar University, Egypt ${ }^{[2]}$.

Corresponding author: Ragab mahmoud E. Ragab

Email: ragab.git@domazhermedicine.edu.eg

Received at: October 05, 2020; Revised at: December 08, 2020; Accepted at: December 09, 2020

DOI: 10.21608/ijma.2020.45279.1188

\section{ABSTRACT}

Background: Ulcerative colitis [UC] is an inflammatory disease of the colon with a relapsing-remitting course. Early diagnosis is crucial, and the presence of a screening test is of utmost importance. Bowel ultrasound could be used as a screening tool for UC.

Aim of the work: To assess the diagnostic accuracy of bowel ultrasound in detecting disease activity and severity in adult patients with UC, compared with lleocolonoscopy as the reference standard.

Patients and methods: This prospective study included 42 adult patients with an established UC diagnosis for at least six months. All patients were subjected to full inquiry about their disease history, complete clinical examination, laboratory investigations, colonoscopy, and bowel ultrasound of the abdomen with Doppler mapping.

Results: Colonoscopy revealed that $41 \%$ in remission and $59 \%$ in an activity. Thirty patients had left-sided, and 12 had an extensive UC. White blood cells, platelet count, erythrocyte sedimentation rate, and C- reactive protein significantly increased in patients with activity versus remission. But, hemoglobin concentrations significantly decreased. Colonic wall thickness significantly increased in patients with activity versus remission $[5.17 \pm 0.74$ vs. $2.57 \pm 0.24$, respectively]. Hypoechogenic or lost colonic wall pattern, enlarged mesenteric lymph nodes and Doppler colonic wall-flow significantly increased in cases with disease activity versus remission $[32.0 \%$, $24.0 \%$ and $72.0 \%$ vs $0.0 \%, 0.0 \%$ and $0.0 \%$ respectively].

Conclusion: Transabdominal bowel ultrasound had a beneficial role in diagnosing ulcerative colitis. It could be used as a screening tool for rapid diagnosis or follow up of treatment.

Keywords: Ultrasound; Bowel; Ulcerative Colitis; Inflammatory Bowel Disease; Colonoscopy.

This is an open-access article registered under the Creative Commons, ShareAlike 4.0 International license [CC BY-SA 4.0] [https://creativecommons.org/licenses/by-sa/4.0/legalcode.

Please cite this article: Ragab RME, Heiza M, Elmola Kh, Shaqueer MM. The role of Trans-abdominal Ultrasound in Assessing
Disease Activity and Severity in Ulcerative Colitis. IJMA 2021; 3[1]: 1119-1124. DOI: 10.21608/ijma.
2020.45279.1188.

* Main subject and any subcategories have been classified according to the research topic. 


\section{INTRODUCTION}

Ulcerative colitis [UC] is a chronic idiopathic inflammatory disorder that causes mucosal inflammation of the colon and characterized by a relapsing-remitting clinical course ${ }^{[1]}$. Activity and severity of inflammation influence management and treatment modality of UC patients. lleocolonoscopy [CS] is considered the first-line procedure for the assessment of $\mathrm{UC}\left[{ }^{[2]}\right.$.

Mucosal healing, defined by a Mayo score of 0 1 , is recommended as the therapeutic goal in clinical practice[3]. However, lleocolonoscopy is an invasive procedure that may increase bowel perforation risk, particularly in severe flare cases ${ }^{[4]}$. In addition, it causes discomfort, and patients do not well accept repeated colonoscopies. Bowel ultrasound [BUS] is a well-tolerated, non-invasive, non-radiating, cheap, easy-to-use tool to manage UC patients in clinical practice. Up to now, there are only a few data evaluating the accuracy of BUS in assessing disease activity and severity of UC [5].

Bowel ultrasound is a relatively new modality as applied to intestinal imaging. Oral bowel preparation is typically not required or utilized before a routine abdominal US[6]. Fasting six hours before the examination reduces air in the bowel that may hamper the investigation. Oral administration of agents such as polyethylene glycol may improve image quality and diagnostic accuracy[7]. BUS for IBD often requires high frequency [5-17 MHz] linear array probes to increase the resolution and to allow adequate assessment of the intestinal wall[8]. Doppler assessment provides additional vascular information and may assist in differentiating predominantly inflammatory from fibrostenotic lesions. Several potential indications for ultrasound exist for patients with ulcerative colitis. The ileocecal region, sigmoid-, ascending- and descending colons are adequately visualized in most patients, whereas visualizing the entire transverse colon can be challenging because of its variable anatomy and position[i].BUS has been utilized to define the anatomical location and severity of UC in patients with established disease and to assess complications [10]. Multiple features of active colonic inflammation have been described based on BUS images. This includes wall thickening $[>3 \mathrm{~mm}]$, complete or relative preservation of the echo-stratification of the colonic wall [except in severe disease], and loss of the haustra coli profile [7]. Trans-abdominal ultrasound examination of extra-luminal phenomena such as mesenteric lymph nodes also may reflect disease activity, but clinical data corroborating such a view are scanty[11].

\section{AIM OF THE WORK}

The study aims to assess the diagnostic accuracy of Bowel ultrasound in detecting disease activity and severity in adult patients with UC, compared with lleocolonoscopy, as the reference standard.

\section{PATIENTS AND METHODS}

This prospective study was carried out on 42 adult patients with an established diagnosis of UC for at least six months attending Al-Azhar university hospital [Damietta], for scheduled follow-up colonoscopy or with disease activity at the period between September 2019 to June 2020.

For inclusion criteria, we only included adult patients with an established diagnosis of UC for at least six months, who had disease activity, and give his/her consent to participate in the study after a full explanation of the study protocol. On the other side, the patient was excluded if he refused to participate, uncooperative, clinically unstable, had or suspected to had colonic perforation, had toxic megacolon, received inadequate bowel preparation, pregnant females, and patients with recent myocardial infarction.

All patients subjected to full inquiry about their disease history, complete clinical examination [general, abdominal and per-rectal], laboratory investigations [complete blood count, coagulation profile, and acute phase reactants mainly ESR and CRP], and colonoscopy and bowel ultrasound [done by single radiologist] of the abdomen with Doppler mapping.

Colonoscopy was performed on all patients under sedation, and all findings were recorded. In detail, an IV line was inserted. All subjects were examined while conscious under light sedation with midazolam [Dormecum]. Hyoscine butyl bromide [buscopan] was sometimes used as antispasmodic. Per rectal [PR], the examination was done first in all cases. When the patient is fully 
relaxed, the endoscope was gently inserted into the anus with an adequate amount of lubricating gel to ensure smooth insertion and reduce the patient's discomfort during the endoscope's advance. The assistant maintains the shaft position while the endoscopist manipulates the control knobs to avoid them from slipping back.

Slow advancement of the endoscope is allowed as long as clear lumen can be seen. Air inflation was used intermittently to facilitate the passage of the endoscope. Manipulation of knobs, torque maneuver, hooking, and external pressure applied to endoscope through the abdominal wall or changing the patient position to supine may be applied to bypass the colon's flexures of acute bends. Sometimes, it is needed to partially withdraw the endoscope and re-advanced either to avoid loop formation or to gain bunkering effect of the colon. The endoscope was advanced till the ileocecal valve is reached; that isn't an easy job. The endoscopic examination was done under the supervision of the specialist professor. An endoscopic scoring system for ulcerative colitis was used Mayo endoscopic sub-score[5]. [Score 0: Normal or inactive disease. Score 1: Mild disease [erythema, decreased vascular pattern, mild friability]. Score 2: Moderate disease [marked erythema, absent vascular pattern, friability, erosions]. Score 3: Severe disease [spontaneous bleeding, ulceration]].

Bowel ultrasound of the abdomen with Doppler mapping: All Patients were prepared with fasting six hours before the examination reduces air in the bowel that may hamper the examination[7]. Intake of water [1.5-2 liters] in one hour preceding the examination. In the first phase, using the conventional grey-scale ultrasonography, the intestine was scanned with the $2.5-3.5 \mathrm{MHz}$ convex transducer, which allows the identification of the involved intestinal segments. The intestinal exploration could then be done accurately by using high-resolution ultrasonography at high-frequency transducers [5-17MHz]. We used high frequency [5-17 MHz] linear array probes to increase the resolution and to allow adequate assessment of the intestinal wall[8]. The normal bowel wall's typical sonographic appearance consists of five concentric, alternately echogenic, and hypoechoic layers that we describe from the lumen outward.
First, a small echogenic layer is seen that reflects the superficial mucosal interface. The deep mucosa, including the muscularis mucosa, is seen as a second hyperechoic layer. A third hyperechoic layer is produced by the submucosa and the muscularis propria interface. The muscularis propria is seen as a fourth hypoechoic layer. Finally, the serosa's marginal interface is seen as the fifth small hyperechoic layer. The average thickness of the normal gut wall is $2 \mathrm{~mm}$. Wall thickness $>3 \mathrm{~mm}$ is considered abnormal. Also, the presence of enlarged mesenteric lymph nodes [short axis $>5$ $\mathrm{mm}$ ] was investigated [5]. Doppler ultrasound was able to visualize "inflammatory hyperemia," which is considered a fairly reliable sign of active inflammation. Colonic wall-flow [CWF] is defined as absence [0] or presence [1] of blood signals at power Doppler [5].

Data analysis: The collected data was subjected to statistical analysis by a program called statistical package for social sciences [SPSS], version 19, running on a personal desktop computer with Microsoft Windows operating system. Mean, median, standard deviation, minimum and maximum were used to express numerical variables, while percentages and numbers were used to express qualitative data. Student " $t$ " test, Mann-Whitney "U" test, and Chi-square or Fisher Exact tests were used to comparing groups according to the data type. P-value $<0.05$ was considered significant.

\section{RESULTS}

This study was conducted on 42 patients with an established UC diagnosis for at least six months, irrespective of disease activity and current therapy. The mean age of studied patients is $30.4 \pm 8.6$ years, males were 16 [38.0\%], and females were 26 [62.0\%]. Colonoscopy revealed that there were 17 patients [41\%] who were endoscopically in remission [Mayo score 0, 1], 25 patients [59\%] were in endoscopic activity [Mayo score 2-3]. In addition, 30 patients [72\%] had left-sided ulcerative colitis and 12 patients [28\%] had an extensive ulcerative colitis [Table 1].

There was a statistically significant increase in WBCs, platelets count, ESR and CRP in patients with endoscopic activity [Mayo 2.3] compared with patients of endoscopic remission [Mayo 0, 1]. In 
addition, there was a statistically significant decrease of hemoglobin concentrations in patients of endoscopic activity [Mayo 2.3] when compared with patients of endoscopic remission [Mayo 0,1]. [Table 2].

There was a statistically significant increase in colonic wall thickness [CWT] in patients of endoscopic activity [Mayo 2, 3] when compared to patients of endoscopic remission [Mayo 0,1$]$ [5.17 \pm 0.74 vs. $2.57 \pm 0.24$ respectively] [Table 3].
There was a statistically significant change in colonic wall pattern [CWP] to hypoechogenic or lost in patients of endoscopic activity [Mayo 2, 3] when compared to patients of endoscopic remission [Mayo 0.1] [32.0\% vs. 0.0\%]. Similarly, there was statistically significant increase in presence of enlarged mesenteric lymph nodes, and Doppler colonic wall flow in patients of endoscopic activity [Mayo 2, 3] when compared with patients of endoscopic remission [Mayo 0,1$]$ ] [24\%, $72.0 \%$ vs $0.0 \%, 0.0 \%$ respectively] [Table 4 ].

Table [1]: Colonoscopy Characteristics of studied patients

\begin{tabular}{|c|c|c|}
\hline \multicolumn{2}{|c|}{ Characteristic } & Percentage \\
\hline $\begin{array}{r}\text { Disease extent at diagnosis } \\
\text { - Left } \\
\text { - Ext }\end{array}$ & & $\begin{array}{l}30[72 \%] \\
12[28 \%]\end{array}$ \\
\hline Mayo endoscopic sub-score & Remission $[1,2]$ & $17[40.47 \%]$ \\
\hline & Active $[2,3]$ & $\begin{array}{ll}25 & {[59.52 \%]}\end{array}$ \\
\hline
\end{tabular}

Table [2]: Relation between disease activity and laboratory data of the studied patients

\begin{tabular}{|l|c|c|c|}
\hline \multicolumn{1}{|c|}{ Laboratory findings } & Mayo 0,1 $[\mathrm{n}=\mathbf{1 7}]$ & Mayo 2,3 $[\mathrm{n}=\mathbf{2 5}]$ & P-value \\
\hline $\mathrm{CRP}[\mathrm{mg} / \mathrm{l}][$ Mean $\pm \mathrm{SD}]$ & $4.6 \pm 2.95$ & $23.6 \pm 17.28$ & $0.0001^{*}$ \\
\hline $\mathrm{ESR}[$ Mean $\pm \mathrm{SD}]$ & $15 \pm 9.6$ & $38.9 \pm 20.1$ & $0.0001^{*}$ \\
\hline $\mathrm{WBCs}\left[\mathrm{x} 10^{3}\right] / \mathrm{cmm}$ & $7.4 \pm 1.7$ & $11.7 \pm 2.1$ & $0.0001^{*}$ \\
\hline $\mathrm{Hb}[\mathrm{g} / \mathrm{d}]$ & $13 \pm 1.3$ & $11.1 \pm 1.3$ & $0.0001^{*}$ \\
\hline $\mathrm{PLT}\left[\mathrm{x} 10^{3}\right] / \mathrm{cmm}$ & $286.2 \pm 43.6$ & $442 \pm 97.5$ & $0.0001^{*}$ \\
\hline $\mathrm{INR}$ & $1.19 \pm .18$ & $1.19 \pm .21$ & 0.973 \\
\hline
\end{tabular}

Table [3]: Colonic wall thickness [CWT] measured by ultrasound among studied groups

\begin{tabular}{|c|c|c|c|c|c|}
\hline \multirow{2}{*}{ Group } & \multicolumn{3}{|c|}{ CWT } & \multirow{2}{*}{ P-value } \\
\cline { 2 - 5 } & Min. & Max. & Mean \pm SD. & Median & p $<0.001^{*}$ \\
\hline Mayo 0,1 & 2.1 & 3.0 & $2.57 \pm .24$ & 2.6 & \\
\hline Mayo 2,3 & 4.0 & 6.4 & $5.17 \pm .74$ & 5.1 & \\
\hline
\end{tabular}

Table [4]: Relation between colonoscopy and ultrasound

\begin{tabular}{|l|c|c|c|}
\hline \multirow{2}{*}{ Ultrasound findings } & \multicolumn{2}{|c|}{ Colonoscopy pattern } & \multirow{2}{*}{ P-value } \\
\cline { 2 - 3 } & Mayo 0,1[n=17] & Mayo 2,3 [n = 25] & \\
\hline Hypoechogenic or lost colonic wall pattern [CWP] & $0[0.0 \%]$ & $8[32.0 \%]$ & $0.009^{*}$ \\
\hline Enlarged mesenteric & $0[0.0 \%]$ & $6[24.0 \%]$ & $0.09^{*}$ \\
\hline Doppler [colonic wall flow] & $0[0.0 \%]$ & $18[72.0 \%]$ & $<0.001^{*}$ \\
\hline
\end{tabular}

\section{DISCUSSION}

The current work revealed a significant increase in acute phase reactant and white blood cells in patients with disease activity compared to patients with disease remission. Platelets significantly increased while hemoglobin concentration significantly decreased among patients with disease activity. These results are supported by Demir et al.[12] who reported a significant increase in ESR, CRP, and WBCs in patients of active UC when compared to patients of remission.
Comparable results were also reported by Cakal et al. [13]. However, they found no significant increase in WBCs in active UC patients. Results of the current work agree with Yesil et al..14], who found a significant reduction of hemoglobin levels in patients of active UC. But, they reported a nonsignificant difference regarding platelet count. The disease's inflammatory nature simply explains the changes observed in acute phase reactants in white blood cells. Otherwise, variations between previous studies and the current one in hemoglobin levels and other $\mathrm{CBC}$ parameters could be explained by 
the individual response of each patient and variations in sample size between different trials.

Ultrasonography is a new modality in applying instinctual imaging, with no need for specific bowel preparation[6]. Its advantages include the rapid evaluation of bowel wall thickness and stratification that reflects alterations in histopathology in UC[15]. The common cut-off value between normal and pathological wall thickness is typically $3 \mathrm{~mm}^{[16]}$. Visualization of the bowel's vascularization using power and color Doppler sonography and visualization of extra-luminal structures are the second and third advantages of trans-abdominal ultrasound[11,15],

In the current trial, colonic wall thickness significantly increased in patients with active UC when compared to patients with UC remission. This is consistent with Allocca et al.[5], who found a significant increase in CWT in patients of endoscopic activity.

On the other side, the results of the current work disagree with Hajiani et al.[17] who found that colonic mural thickness among new cases of ulcerative colitis was significantly more than cases who diagnosed as UC flare up and concluded that ultrasonography is not an ideal tool for evaluation of UC patients because its results could be affected by several factors such as body mass index [BMI] and region of involvement. Different phases of the disease included in their study and current work could explain this controversy.

Current results revealed a significant change in colonic wall pattern to the hypoechogenic or lost pattern in patients with active UC compared to remission $[32 \%$ vs. $0.0 \%]$.Similarly, there was significant increase in presence of enlarged mesenteric lymph nodes, and Doppler colonic wall flow in patients of endoscopic activity versus remission [Mayo 0, 1] [24\%, $72.0 \%$ vs $0.0 \%, 0.0 \%$ respectively]. These results reflected the US's power to recognize different pathologies and their association with colonoscopy results. This is in agreement with previous literature. For example, Allocca et al. [5] found a significant change in CWP to the hypoechogenic or lost pattern in [29\%] of patients with endoscopic activity when compared to remission [0\%]. They also reported chronic wall flow in [66\%] of patients with endoscopic activity, compared to none in patients in remission, and lymph node enlargement was observed in $23 \%$ of endoscopic activity. In contrast, no enlargement was found in patients with remission. In addition, Bezzio et al. ${ }^{[18]}$ reported that alteration of bowel wall echo pattern, loss of haustra coli, and especially BWT of more than $3 \mathrm{~mm}$ has been strongly correlated with $\mathrm{C}$-reactive protein values and the endoscopic score.

Our results also agree with Calabrese et al.[19] who reported that Mesenteric lymph nodes are another nonspecific sign of intestinal inflammation that may be seen during active disease and chronic intestinal inflammation.

Finally, Kinoshita et al.[20] concluded that transabdominal US might be a useful modality to evaluate UC, as there was moderate concordance between ultrasound and colonoscopy. The US being radiation-free and non-invasive modalities is an advantageous tool and could be used as a screening tool like computed tomography and magnetic resonance imaging to assess disease activity.

In short, the results of the current work highlighted the potential beneficial role of transabdominal ultrasound in the diagnosis of ulcerative colitis. It could be used as a screening tool for rapid diagnosis or follow up of treatment.

Financial and Non-financial Relationships and Activities of Interest

None

\section{REFERENCES}

1. Assadsangabi A, Evans CA, Corfe BM, Lobo A. Application of Proteomics to Inflammatory Bowel Disease Research: Current Status and Future Perspectives. Gastroenterol Res Pract. 2019 Jan 15; 2019:1426954. doi: 10.1155/2019/1426954.

2. Magro F, Gionchetti P, Eliakim R, Ardizzone S, Armuzzi A, Barreiro-de Acosta M, et al; European Crohn's and Colitis Organisation [ECCO]. Third European Evidence-based Consensus on diagnosis and 
management of ulcerative colitis. Part 1: Definitions, diagnosis, extra-intestinal manifestations, pregnancy, cancer surveillance, surgery, and ileoanal pouch disorders. J Crohns Colitis. 2017 Jun 1; 11[6]:649670. doi: 10.1093/ecco-jcc/jjx008.

3. Peyrin-Biroulet L, Sandborn W, Sands BE, Reinisch W, Bemelman W, Bryant RV, et al. Selecting Therapeutic Targets in Inflammatory Bowel Disease [STRIDE]: Determining Therapeutic Goals for Treat-to-Target. Am J Gastroenterol. 2015 Sep;110[9]:1324-38. doi: 10.1038/ajg.2015.233.

4. Crews NR, Bohm ME. Complications of Inflammatory Bowel Disease: Initial Medical Management and Role of Endoscopy. Chapter 12, In: Lim R. [eds] Multidisciplinary Approaches to Common Surgical Problems. Springer, Cham. 2019; pp: 115-122 https://doi.org/10.1007/978-3-030-12823-4_12

5. Allocca M, Fiorino G, Bonovas S, Furfaro F, Gilardi D, Argollo M, et al. Accuracy of Humanitas Ultrasound Criteria in Assessing Disease Activity and Severity in Ulcerative Colitis: A Prospective Study. J Crohns Colitis. 2018 Nov 28; 12[12]:1385-1391. doi: 10.1093/ ecco-jcc/jjy107.

6. Bryant RV, Friedman AB, Wright EK, Taylor KM, Begun J, Maconi G, Maaser C, et al. Gastrointestinal ultrasound in inflammatory bowel disease: an underused resource with the potential paradigm-changing application. Gut. 2018 May;67[5]:973-985. doi: 10. 1136/gutjnl-2017-315655.

7. Deepak $P$, Bruining DH. Radiographical evaluation of ulcerative colitis. Gastroenterol Rep [Oxf]. 2014 Aug;2[3]:169-77. doi: 10.1093/gastro/gou026.

8. Biernacka KB, Barańska D, Grzelak P, Czkwianianc E, Szabelska-Zakrzewska K. Up-to-date overview of imaging techniques in the diagnosis and management of inflammatory bowel diseases. Prz Gastroenterol. 2019; 14[1]:19-25. doi: 10.5114/pg.2019.83423.

9. Pellino G, Keller DS, Sampietro GM, Carvello M, Celentano V, Coco C, et al.; Italian Society of Colorectal Surgery SICCR. Inflammatory bowel disease position statement of the Italian Society of Colorectal Surgery [SICCR]: ulcerative colitis. Tech Coloproctol. 2020 May; 24 [5]:397-419. doi: 10.1007/s10151-02002175-z.

10. Greenup AJ, Novak KL. Bowel Ultrasound Imaging, Protocol and Findings. Chapter 2, In: Rimola J. [eds] Cross-Sectional Imaging in Crohn's Disease. Springer, Cham. 2019; pp 11-34, doi: 10.1007/978-3319-96586-4_2

11. Hirche TO, Russler J, Schröder O, Schuessler G, Kappeser P, Caspary WF, Dietrich CF. The value of routinely performed ultrasonography in patients with Crohn disease. Scand J Gastroenterol. 2002 Oct; 37
[10]: 1178-83. doi: 10.1080/003655202760373399.

12. Demir AK, Demirtas A, Kaya SU, Tastan I, Butun I, Sagcan M, Sahin S, Tasliyurt T, Yilmaz A. The relationship between the neutrophil-lymphocyte ratio and disease activity in patients with ulcerative colitis. Kaohsiung $\mathrm{J}$ Med Sci. 2015;31[11]:585-90. doi: 10.1016/j.kjms. 2015. 10.001.

13. Cakal B, Akoz AG, Ustundag Y, Yalinkilic M, Ulker A, Ankarali $H$. Red cell distribution width for assessment of activity of inflammatory bowel disease. Dig Dis Sci. 2009; 54[4]:842-7. doi: 10.1007/s10620-008-0436-2.

14. Yesil A, Senateş E, Bayoğlu IV, Erdem ED, Demirtunç $R$, Kurdaş Övünç AO. Red cell distribution width: a novel marker of activity in inflammatory bowel disease. Gut Liver. 2011;5[4]:460-7. doi: 10.5009/gnl.2011.5.4.460.

15. Strobel D, Goertz RS, Bernatik T. Diagnostics in inflammatory bowel disease: ultrasound. World J Gastroenterol. 2011 Jul 21;17[27]:3192-7. doi: 10. 3748/wjg.v17.i27.3192.

16. Nylund K, Maconi G, Hollerweger A, Ripolles T, Pallotta N, Higginson A, et al. EFSUMB Recommendations and Guidelines for Gastrointestinal Ultrasound. Ultraschall Med. 2017 Jun;38[3]:e1-e15. English. doi: 10.1055/s0042-115853.

17. Hajiani E, Gharibvand MM, Alavinejad P, lak E, Khedri M. Diagnostic accuracy of ultrasonography in comparison with colonoscopy for diagnosing of ulcerative colitis. Gastroenterol Hepatol Open Access. 2018; 9[5]:224228. doi: 10.15406/ghoa. 2018. 09. 00331

18. Maconi G., Greco S., Porro G.B. Ulcerative Colitis. In: Maconi G., Porro G.B. [eds] Ultrasound of the Gastrointestinal Tract. Medical Radiology [Diagnostic Imaging]. Springer, Berlin, Heidelberg. 2007; pp 7381, https://doi.org/10.1007/978-3-540-49841-4_8

19. Calabrese E, Kucharzik T, Maaser C, MacOni G, Strobel $\mathrm{D}$, Wilson $\mathrm{SR}$, et al. Real-time Interobserver Agreement in Bowel Ultrasonography for Diagnostic Assessment in Patients with Crohn's Disease: An International Multicenter Study. Inflamm Bowel Dis 2018; 24[9], 2001-2006. doi: 10.1093/ ibd/izy091

20. Kinoshita K, Katsurada T, Nishida M, Omotehara S, Onishi $\mathrm{R}$, Mabe $\mathrm{K}$, et al. Usefulness of transabdominal ultrasonography for assessing ulcerative colitis: a prospective, multicenter study. J Gastroenterol. 2019; 54 [6]:521-529. doi: 10.1007/s00535-018-01534-w 


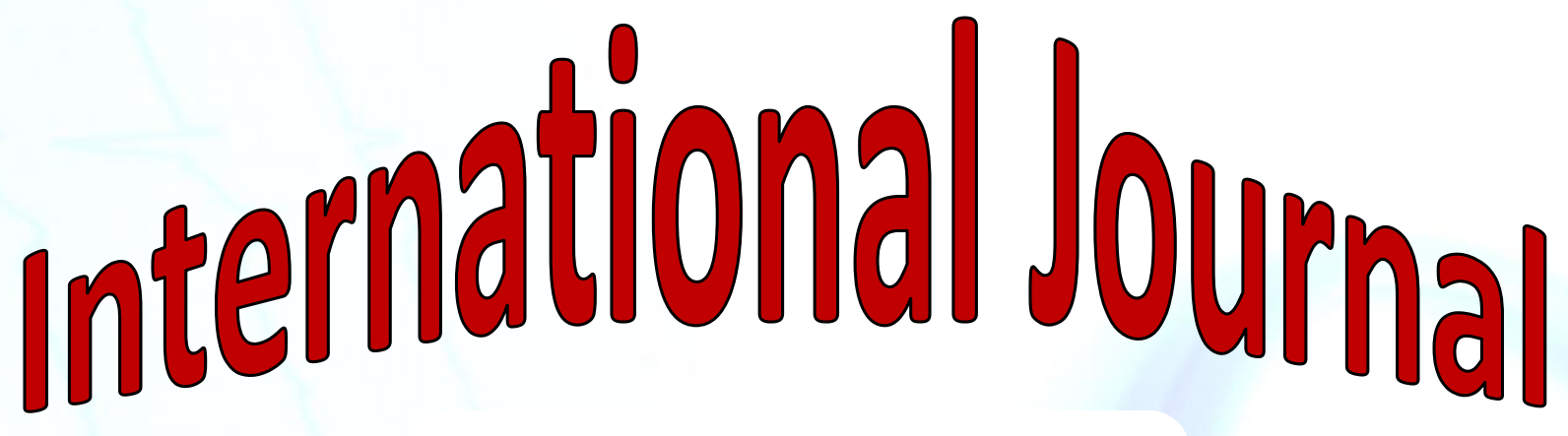

https://ijma.journals.ekb.eg/

Print ISSN: 2636-4174

Online ISSN: 2682-3780

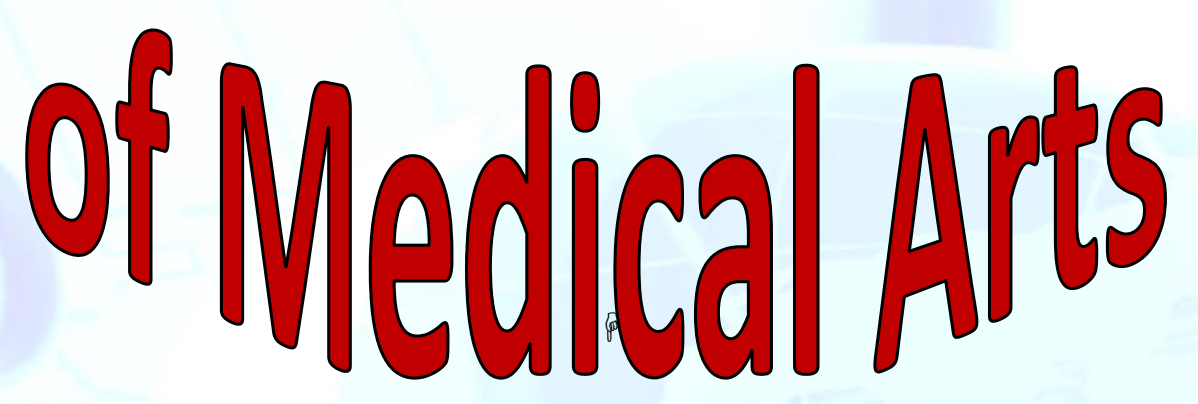

